\title{
Huge Post-Partum Intra-Myometrial Hematoma (Couvelaire Uterus) in A Preserved Uterus in A Case of Placenta Accreta: Case Report
}

Ahmed A. Khalifa*1, Elsemary M.A ${ }^{1}$, Mahmoud Mousa Ahmed ${ }^{1}$, Mariam M. Elshamandy ${ }^{2}$

Departments of ${ }^{1}$ Obstetrics \& Gynecology and ${ }^{2}$ Public Health, Faculty of Medicine - Sohag University, Egypt

*Corresponding author: Ahmed A. Khalifa, Mobile: (+20) 01065337768, E-Mail: ahmed.khalifa@med.sohag.edu.eg

\begin{abstract}
Background: Couvelaire uterus, also known as uteroplacental apoplexy, is a rare but nonfatal condition resulting from extravasation of blood into the uterine musculature and surrounding tissues.

Objective: presentation of a case of huge intramyometrial hematoma (Couvelaire uterus) developed postpartum in a preserved uterus in a case of placenta previa accreta, which is atypical presentation in such cases.

Case Report: 29 years old female patient 38 weeks pregnancy. Pregnancy was terminated by CS due to placenta previa cenralis accreta. During CS, preservation of the uterus was done by application of multiple haphazard haemostatic sutures and bilateral uterine artery ligation. The patient presented by post-partum collapse. Ultrasonographic examination revealed huge intramyometrial hematoma (Cauvlair uterus). Exploration was done with confirmation of the ultrasonographic picture. Subtotal abdominal hysterectomy was done with preservation of both ovaries with uneventful post portative period. Examination revealed huge intramyometrial hematoma (Cauvlair uterus).

Conclusion: Post-partum intramyometrial hematoma (Couvelaire uterus) is atypical presentation in cases of preserved uterus in patients with placenta accreta and it may result from multiple haphazard unorganized haemostatic sutures. Therefore, the obstetricians should be aware of such rare complication for early diagnosis and management.
\end{abstract}

Keywords: Huge post-partum intramyometrial hematoma, Couvelaire uterus, Preserved uterus, Placenta accrete.

\section{INTRODUCTION}

Morbidly adherent placenta (MAP) is considered one of the most life-threatening obstetric complications and may cause severe intra-operative bleeding requiring massive blood transfusion with its related consequences, increased incidence of peripartum hysterectomy and high maternal mortality $(\mathbf{1}, \mathbf{2})$

MAP is the greatest challenge in obstetric ${ }^{(3)}$. Good results and outcomes of MAP depend on early diagnosis and multidisciplinary planning for delivery ${ }^{(4)}$. MAP is classified into three important degrees according to the attachment of chorionic villi to the uterine wall and adjacent organs. It could be placenta accreta (chorionic villi are in contact with the myometrium), placenta increta (chorionic villi invade the myometrium) or placenta percreta (chorionic villi penetrate the uterine serosa). The increased rate of cesarean delivery over the past 50 years is the leading cause of MAP ${ }^{(5)}$. In the last decades, the rate of cesarean section has increased dramatically worldwide ${ }^{(6,7)}$.

Many methods were reported to control bleeding in cases of MAP. Postpartum bleeding or postpartum hemorrhage is often defined as the loss of more than 500 $\mathrm{ml}$ or $1000 \mathrm{ml}$ of blood within the first $24 \mathrm{~h}$ following childbirth. Couvelaire uterus is considered atypical presentation in post-partum patient with no clinical evidence of ante-partum placental separation.

\section{CASE REPORT}

29 years old, female patient was admitted to the emergency unit of obstetrics and gynecology department of Sohag University hospital for elective caesarean section. The obstetric history of the patient demonstrated that she was pregnant at 38 weeks with placenta previa major degree, accreta with no other remarkable risk factors. The patient have four off springs, two males and two female, all of them have been delivered by caesarean section. On admission, the vital data were within normal pulse: 94beat/minute, Bp: 120/70 mmHg and hemoglobin level: $12 \mathrm{gm} / \mathrm{dl}$. Obstetric ultrasonography revealed single living fetus about 38 weeks gestational age with placenta previa centralis accreta with no other abnormal sonographic findings.

No history of vaginal bleeding or labour pain, which was confirmed by obstetric assessment. The patient was counseled about the termination of pregnancy by caesarean section and the possible risks of this operation as regard peripartum hysterectomy and related consequences. Consent for hysterectomy was obtained from the patient and her husband.

The patient was transferred to the operative theatre after availability of all measures in such cases; cross-matched blood, fresh frozen plasma, platelet, anesthesia team and availability of ICU place. Under general anesthesia lower segment caesarean section was done resulted in single living male fetus with massive bleeding at the placental bed which was managed by multiple unorganized haphazard haemostatic sutures and bilateral uterine artery ligation. Intra-operatively, patient received three units of backed RBCs and two units of fresh frozen plasma, abdomen closed after insurance of homeostasis and contracted uterus with intraperitoneal drain insertion. The vital signs of the patient were within normal ranges at the time of termination of the surgery and there was no need for ICU admission. 
Two hours post-partum, there was deterioration in the vital signs ( postpartum collapse); pulse was 120 beat/minute, BP was $90 / 50 \mathrm{mmHg}$, oliguria with no considerable vaginal bleeding, large atonic uterus above the umbilicus and no considerable collection from intraperitoneal drain (less than $100 \mathrm{cc}$ blood). Ultrasonographic examination revealed large subinvoluted uterus with no considerable intrauterine collection. The whole uterine wall was replaced by very large hematoma. In addition, there was no intraperitoneal collection. Post-operative hemoglobin level was $7 \mathrm{gm} / \mathrm{dl}$ with normal coagulation profile. The patient was counseled about exploration and hysterectomy.

Under general anesthesia exploration was done at the previous pfenensteil incision with intra-operative picture of large atonic subinvoluted uterus, bluish in color and occupied by large intramyometrial hematoma (Couvelaire uterus) (Fig. 1). Subtotal hysterectomy with preservation of both ovaries was done. Transfusion of two units of fresh blood and two units of fresh frozen plasma were done. The patient was discharged from the hospital on the fourth postoperative day with uneventful postoperative period.

\section{Ethical approval and patient consent:}

The patient signed informed written consent for the acceptance of the operation and publication of this case report. This work has been carried out in accordance with the Code of Ethics of the World Medical Association (Declaration of Helsinki) for studies involving humans.

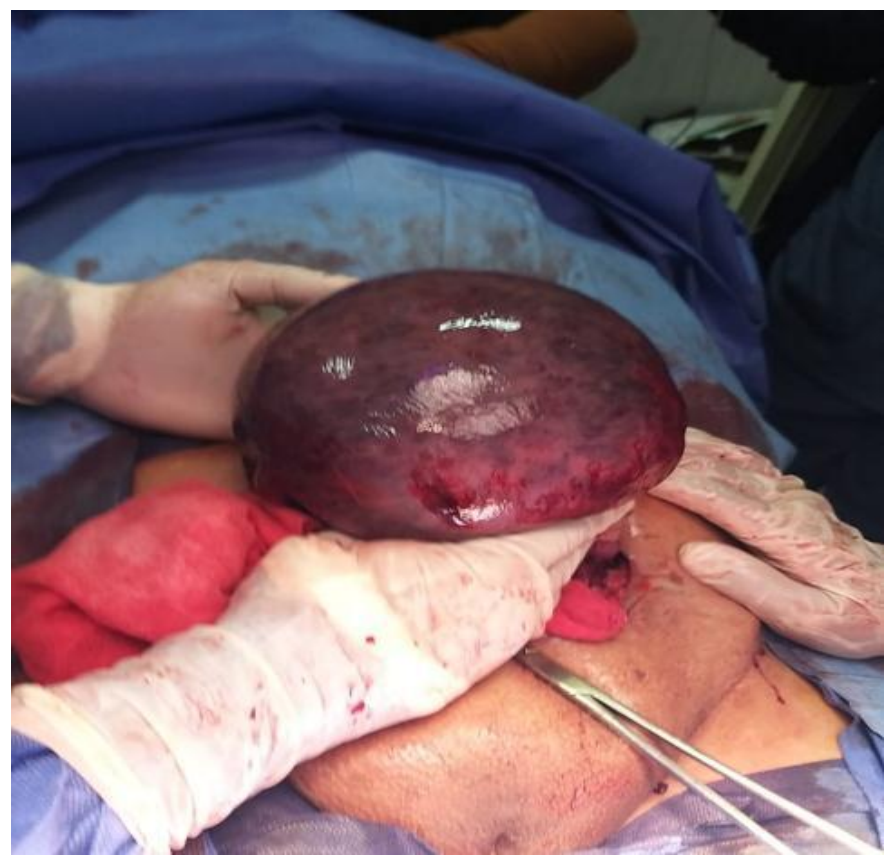

Fig. (1): Picture of intra-operative Couvelaire uterus.
One of the obstetric nightmares nowadays is morbidly adherent placenta (MAP), which represents a life-threatening event to the patients. Morbidly adherent placenta resulted from the abnormal attachment of the chorionic villi to the myometrium. There are three important degrees of morbidly adherent placenta according to its attachment to myometrium: placenta accreta, placenta increta, placenta percreta. Placenta percreta is the most severe form as it penetrates through the whole thickness of myometrium. Massive blood loss may occur during operation of morbidly adherent placenta ${ }^{(8)}$. Multiple complications are associated with the operations of morbidly adherent placenta as massive intra-operative and postoperative bleeding, atonic postpartum hemorrhage, and peripartum hysterectomy $(9,10)$. Morbidly adherent placenta is one of the causes of maternal death (11). As regards many obstetricians, hysterectomy is considered the main line of treatment in morbidly adherent placenta due to its role in decreasing the blood loss intra-operative, postoperative and related complications.

Multiple techniques were reported to improve the outcomes of morbidly adherent placenta and preserve the uterus. One of these techniques is triple procedure that consists of: preoperative placental localization, pelvic devascularization and myometrial excision then reconstruction of the uterine wall ${ }^{(\mathbf{1}, \mathbf{2}, \mathbf{1 2})}$. The attachment of the placenta to the lower uterine segment, which occur in placenta accreta, is the leading cause of massive intra-operative bleeding due to atony. Multiple conventional methods have been used to control bleeding in cases of morbidly adherent placenta as different types of haemostatic compressing sutures, ecbolic drugs, and uterine packing ${ }^{(\mathbf{1 3})}$.

The term of Couvelaire uterus has been described by Alexandre Couvelaire (1873-1948) a pathologic condition that he called uteroplacental apoplexy, but which is better known as Couvelaire uterus. Couvelaire uterus usually is associated with placental separation. The uterus, and occasionally the tubes and ovaries become bluish or purplish in color. It is usually associated with bloody fluid in the broad ligament and even in the peritoneal cavity. In some cases, the uterus become flappy unable to contract and remains atonic even after being emptied vaginally or by cesarean section ${ }^{(\mathbf{1 4})}$. Hysterectomy is often necessary in order to check the continuous bleeding from these atonic uteri, which was in our case. The real cause of this condition is not well understood, except for the fact that it is usually associated with the severest form of abruptio placentae, particularly when the hemorrhage remains concealed. In our case, this condition developed postpartum with absence of placenta with no clinical evidence of ante partum abruptio placentae. It may result from multiple haphazard unorganized haemostatic sutures for controlling bleeding. 
Some authors believe that the blood infiltrates between the muscular fibers of the uterus, reaches the peritoneal surface, and eventually seeps into the peritoneal cavity. The intramuscular hemorrhage dissociates the muscular fibers and, probably through a toxic process, these fibers lose their contractile properties. Similar hemorrhage can be seen in the decidua overlying the muscular area that is infiltrated with blood. It has also been believed that the process is associated with consumption of clotting factors, frequently observed in cases of placental separation. The unclotted blood from the oozing area of placental implantation may infiltrate the surrounding decidua and uterine muscle, giving rise to the ecchymotic areas seen in Couvelaire uterus. This is atypical presentation in cases of preserved uterus in patients with placenta previa, which needs more cases for detection of the cause of such rare complication.

\section{CONCLUSION}

Post-partum intramyometrial hematoma (Couvelaire uterus) is atypical presentation in cases of preserved uterus in patients with placenta accreta and it may result from multiple haphazard unorganized haemostatic sutures. Therefore, the obstetricians should be aware of such rare complication for early diagnosis and management.

\section{REFERENCES}

1. Chandraharan E (2012): Should the Triple-P procedure be used as an alternative toperipartum hysterectomy in the surgical treatment of placenta percreta. Womens Health Lond., 8 (4): 351-3.

2. Chandraharan E, Rao S, Belli A et al. (2012): The Triple$\mathrm{P}$ procedure as aconservative surgical alternative to peripartum hysterectomy for placentapercreta. Int J Gynaecol Obstet., 117 (2): 191-4.

3. Bennett M (2003): "Conservative" management of placenta praevia percreta: report of two cases and discussion of current management options. Aust N Z J Obs Gynaecol., 43: 249-51.
4. Hamilton B, Martin J, Ventura S et al. (2005): Births: preliminary data for 2004. Natl Vital Stat Rep., 54 (8): 117.

5. Singh R, Pradeep Y (2015): Maternal and neonatal outcomes in morbidly adherent placenta: a developing country experience. Trop Doct., 45 (3): 183-7.

6. Souza J, Gulmezoglu A, Lumbiganon $P$ et al. (2010): Caesarean section without medical indications is associated with an increased risk of adverse short-term maternal outcomes: the 2004-2008 WHO Global Survey on Maternal and Perinatal Health. BMC Medicine, 8: 71-78.

7. Usta I, Hobeika E, Musa A et al. (2005): Placenta previaaccreta: risk factors and complications. Am J Obstet Gynecol., 193: 1045-9.

8. Sumigama S, Itakura A, Ota $T$ et al. (2007): Placentapreviaincreta/percreta in Japan: a retrospective study of ultrasound findings,management and clinical course. J ObstetGynaecol Res., 33 (5): 606-11.

9. Rossi A, Lee R, Chmait R (2010): Emergency postpartum hysterectomy for un-controlled postpartum bleeding: a systematic review. Obstet Gynecol., 115 (3): 637-44.

10. Awan N, Bennett M, Walters W (2011): Emergency peripartum hysterectomy: a10-year review at the Royal Hospital for Women, Sydney. Aust N Z J Obstet Gynaecol., 51 (3): 210-5.

11. Eller A, Bennett M, Sharshiner M et al. (2011): Maternal morbidity in cases of placenta accreta managed by a multidisciplinary care team compared with standard obstetric care. Obstet Gynecol., 117 (2 Pt 1): 331-337.

12. Teixidor V, Belli A, Arulkumaran $S$ et al. (2015): Prevention of postpartum-hemorrhage and hysterectomy in patients with morbidly adherent placenta: a cohort study comparing outcomes before and after introduction of the Triple-P procedure. Ultrasound Obstet Gynecol., 46 (3): 350-5.

13. Ballas J, Hull A, Saenz C et al. (2012): Preoperative intravascular balloon catheters and surgical outcomes in pregnanciescomplicated by placenta accreta: a management paradox. Am J Obstet Gynecol., 207 (3): 216-222.

14. Habek D, Selthofer R, Kulas T (2008): Uteroplacental apoplexy (couvelaire syndrome). Wien Klin Wochenschr., 120: 88-94. 